\title{
El concepto de poder en la administración
}

Luis Antonio Cruz Soto Facultad de Contaduría y Administración, Universidad Nacional Autónoma de México lcruz@fca.unam.mx
Nadie negará la situación amenazante que se dispone a transformar en una función del engranaje a todo individuo, lo sepa o no. Pero, para salir al paso a esta amenaza, hay que desnudarla del pathos metafísico que paraliza la conciencia. Esta conciencia se ve reflejada por el manejable concepto del miedo, él mismo ya un pedazo de ideología.

Th. W. Adorno

\section{Resumen}

El objetivo de este trabajo consiste en explorar el concepto de poder en la administración. Lo que nos interesa estudiar es la dominación que se ejerce desde una posición de dominio establecida formalmente en la organización. En este trabajo sostenemos que lo que define el poder es la legalidad, mientras que a la autoridad, la legitimidad. En primer lugar realizaremos un breve análisis de la distinción entre legalidad y legitimidad con el fin de distinguir el concepto de poder del de autoridad; posteriormente, analizamos el concepto del poder, distinguiendo el poder que otorga el aparato de dominio del poder que se establece a partir de las relaciones intersubjetivas, que se definen como las relaciones de poder; finalmente, realizamos una aproximación conceptual del poder en la administración y algunas críticas inherentes a esta forma de dominio.

Palabras clave: poder, autoridad, legitimidad, legalidad. 


\title{
The concept of power in administration
}

\begin{abstract}
The objective of this work is to explore the concept of power in Administration. What we are interested in studying is the domination exerted from a dominant position in the organization formally established. In this paper we argue that what defines power is the legality, and what defines authority is legitimacy. In the first place we will have a brief discussion of the distinction between legality and legitimacy, in order to distinguish the concept of power from authority. Then, we analyze the concept of power, distinguishing the power that gives the dominant device from the power established in intersubjective relationships, which are defined as relationships of power. Finally, we perform a conceptual approach of the power in Administration and some criticism inherent to this form of domination.
\end{abstract}

Keywords: power, authority, legitimacy, legality.

\section{Introducción}

El objetivo de este trabajo consiste en explorar el concepto de poder en la administración. Lo que nos interesa estudiar es la dominación que se ejerce desde una posición de dominio establecida formalmente en la organización. En este trabajo sostenemos que lo que define el poder es la legalidad, y a la autoridad, ${ }^{1}$ la legitimidad (Cruz, 2010). Primero realizaremos un breve análisis de la distinción entre legalidad y legitimidad, con el fin de distinguir el concepto de poder del de autoridad; después, analizamos el concepto del poder, distinguiendo el poder que otorga el aparato de dominio del poder que se establece a partir de las relaciones intersubjetivas, que se definen como las relaciones de poder; finalmente, realizamos una aproximación conceptual del poder en la administración y algunas críticas inherentes a esta forma de dominio.

\footnotetext{
${ }^{1}$ Entenderemos por autoridad, según la definición de Walter Buckley (1993, p. 271), como el individuo que dispone del control de la conducta de los actores para la promoción de metas colectivas, basada en alguna forma discernible de consentimiento cognoscible de éstos. La autoridad implica una sujeción informada y voluntaria, que es un estado psicológico definido y una coordinación o identidad de las orientaciones hacia metas de todos los que participan en la dominación. El concepto de autoridad se explica por el carácter legítimo de la dominación; quienes asumen su condición de dominados lo hacen de manera racional y voluntaria por estar inmersa en el consenso informado, al margen de los elementos coactivos de dominio.
} 
Las organizaciones se definen como espacios de acción en el que se desarrollan diversas actividades tendientes al logro de determinados objetivos, razón por la cual consideramos que lo que define su dinámica es la interacción de los individuos, los cuales responden a ciertas directrices de participación para la realización de determinadas funciones. En primera instancia, los mecanismos de orientación de las tareas están condicionados por la estructura formal, dentro de la cual se incluyen la estructura de dominación, ${ }^{2}$ por medio de la jerarquía y la estructura operativa que expresa la definición de puestos. El cuerpo normativo del que se vale la organización para alcanzar sus objetivos funge como el elemento más visible que permite esperar un tipo de conducta de los actores, independientemente de sus directrices subjetivas que los definen, como su dimensión social o cultural (Cruz, 2008).

Sin embargo, la interactuación individual que se produce en el ámbito de la administración, a partir de la estructura orgánica, tiene su principal referente en la realización concreta de las acciones, que no responden exclusivamente al sistema de control formal imperante para alcanzar la coordinación de los actores, sino que obedecen a la relación intersubjetiva que se produce entre ellos; en este sentido, las directrices de comportamiento en la administración ya no sólo responden a lo establecido por la estructura formal, sino que se extiende a una dinámica propia de funcionamiento de los individuos, que generan un tipo de conducta colectiva al margen de los elementos coactivos de dominio dispuestos por la dominación formal. Estos mecanismos de participación individual y colectiva dan origen a la comprensión de la legitimidad.

La autoridad y el poder brindan explicaciones divergentes a la relación existente entre quienes ejercen la dominación y los que son dominados en el ámbito organizacional, dispuesto por lo administración. La diferencia conceptual que proponemos entre la autoridad y el poder se define por la legitimidad. Mientras la autoridad obedece a una forma de actuación social que se caracteriza por aspirar a una legi-

\footnotetext{
${ }^{2}$ Tomamos el concepto de dominación para distinguir una relación de mando y obediencia de los conceptos de autoridad y poder. Entenderemos por dominación, según el concepto de Max Weber (1999, p. 43), como "la probabilidad de encontrar obediencia a un mandato de determinado contenido entre personas dadas"; en este sentido, la dominación significa la atribución subjetiva u objetiva que tienen ciertos sujetos sobre la voluntad de otros para la realización de las acciones. El concepto de dominación puede aludir tanto a la vertiente coercitiva de dominio o a la manipulación de la voluntad como a la posibilidad de asumir las directrices de acción de manera plenamente consciente y voluntaria, cómo máximas de obrar (Weber, 1999, p. 170), donde el sustento principal es la creencia racional de una orden.
} 
timación constante, capaz de validar su proceder en las acciones concretas o por cualquier otro medio reconocido como válido por una colectividad, el poder es una forma de dominio en la que se impone un sistema de control sobre los demás, por cualquier medio provisto para ello, sin apelar necesariamente a la legitimación. El tener una posición formal de dominio, cualquiera que ésta sea, es motivo suficiente para el ejercicio del poder, independientemente de la aceptación consciente y libre de una persona o grupo de individuos sobre quienes se ejerce la dominación.

\section{La legalidad y la legitimidad en la administración}

La legalidad y la legitimidad en la administración condicionan las formas de comportamiento de los individuos en las organizaciones. La primera se sustenta en las normas establecidas por la organización que permiten orientar el trabajo conjunto dispuesto por la estructura orgánica a través de la estructura jerárquica, líneas de mando, división funcional y una serie reglas, ordenamientos y procedimientos que condicionan el actuar de los individuos dentro de las organizaciones; en tanto la legitimidad, a diferencia de la legalidad, carece de un aparato de dominación: su principal sustento es el acuerdo intersubjetivo de los individuos que aspira a una validación constante de las acciones, mediante el juicio racional, informado y voluntario de los actores que participan en un ámbito de funcionamiento establecido. Mientras la legalidad dispone de un sistema de control jerárquico, la legitimación funge como un ámbito de justificación funcional sin una jerarquía formal establecida.

La estructura orgánica, de la que emana el contenido normativo en una organización, garantiza una continuidad ordenada de funcionamiento que articula diversas actividades y procesos que le permiten a la organización el cumplimiento de sus objetivos. Esta estructura formal predispone a los actores al cumplimiento de ciertas funciones, pero no garantiza plenamente su adecuado funcionamiento, pues éste se encuentra condicionado a la realización concreta de las tareas. El sistema de control legalizado en las organizaciones es impersonal, debido a que por sí mismo funge como una fuente de dominación, independientemente del individuo que lo asuma, y responde a mecanismos implícitos y explícitos de coacción, como últimos garantes del orden establecido. En este sentido, no es necesario el acuerdo intersubjetivo de los actores, como sucede en la legitimidad, pues el reconocimiento a este sistema de dominación se valida aun antes de que los individuos asuman su condición funcional porque así se encuentra establecido en el propio orden normativo imperante. 
No podemos excluir la posibilidad muy real de que para una elevada proporción de actores de cualquier sistema social se acepten y obedezcan las normas simplemente como condiciones dadas de la acción, con escasa comprensión de su origen y su justificación ideológica, y con inteligencia aún menor de que podría adoptar otra forma, y de que otra proporción notable se siente oprimida por las normas y las sigue con renuencia porque no parece posible ajustarse a otro curso de acción (Buckley, 1993, pp. 285-286).

La legitimidad en sí misma no es una condicionante de dominio, sino que es una aspiración subjetiva de quienes ejercen la dominación para justificar un modo y orientación de comportamiento colectivo, que no se encuentra sustentado en ningún orden establecido: se construye a través de un acuerdo reconocido como válido por todos los actores. A diferencia de la legalidad, la legitimidad es un ámbito de reconocimiento personal que se otorga implícita o explícitamente a un individuo, al margen del aparato de dominio, por lo que no dispone del elemento coactivo de control, sino que tiene su fundamento en la colectividad que reconoce la validez de las acciones, lo que permite un cierto control social diferente al emanado de la legalidad. En la legitimidad, el control social se explica a partir de la justificación racional de las acciones que los individuos la asumen como máximas de obrar, en tanto que en la legalidad el control social se explica a partir de una condicionante impuesta por el propio aparato de dominio, asumida por los actores como una necesidad inapelable. Walter Buckley señala que la legalidad se caracteriza por aspirar a un control de la conducta, aun contra su voluntad y sin un compromiso o comprensión esclarecidos; en tanto que en la legitimidad el control social se orienta a partir del consentimiento o consenso informado o comprometido de la colectividad organizada (Buckley, 1993, pp. 258-259).

La relación de dominio que emana de la administración apela a la legalización como una forma efectiva de orientar las actividades colectivas; asimismo, todas las acciones que emprende quien ejerce la dominación deben estar condicionadas por algún tipo de legitimación, por mínima que ésta sea. Para Buckley (1993, pp. 259-260), la vertiente de legitimación legalizada, fundada más en la imposición que proyecta la dominación que en el reconocimiento de los individuos, tiende a generar la división y el disenso grupales, así como sistemas coercitivos de control institucional que pueden mantener un cierto "orden social" de sumisión externa durante periodos más o menos prolongados; en tanto la legitimidad fundada en el consentimiento colectivo de los miembros que conforman una organización funge como una estructura conjunta de promoción de metas individuales y colectivas, y 
del consenso grupal conexo, concebido en términos de perspectivas compartidas y de compromiso emotivo.

Tanto la legalidad como la legitimidad ofrecen significados de conducta diversos. Por un lado, la legalidad permite la asunción de una manera de conducta sustentada en la estructura formal orientada al logro de los objetivos organizacionales; esto es, la determinación normativa que proyecta la estructura orgánica permite, inicialmente, una directriz de legitimación, y los individuos la asumen como válida en el propio desarrollo de sus actividades dentro de la organización; en este sentido, quien ejerce la dominación es el aparato de dominio. Por otro lado, en la legitimidad los actores justifican las acciones que se realizan en la organización, y ofrece la oportunidad de reconocer a la persona que ejerce la dominación, al margen de la estructura formal.

La forma de legitimidad hoy más corriente es la creencia de la legalidad: la obediencia a preceptos jurídicos positivos estatuidos según el procedimiento usual y formalmente correctos. La contraposición entre ordenaciones pactadas y "otorgadas" es sólo relativa. Pues cuando una ordenación pactada no descansa en un acuerdo por unanimidad - como con frecuencia se requería en la Antigüedad para que existiera legitimidad auténtica-, sino más bien en la sumisión de hecho, dentro de un círculo de hombres, de personas cuya voluntad es empero discordante de la de la mayoría, tenemos en realidad una ordenación otorgada -impuesta - respecto de esas minorías (Weber, 1999, p. 30). ${ }^{3}$

La atribución que le otorga Max Weber a la legalidad como una forma de legitimidad es la que ha prevalecido en la teoría de la administración; por ejemplo, George Terry define a la legitimidad como "[...] la autoridad formal existente en la organización formal e incluye los títulos de los puestos, los derechos por tomar decisiones en general y el poder aceptado concedido al titular de un puesto formalmente definido" (1982, p. 336). La atribución de una norma como legítima en la administración descansa en la posibilidad de validar la acción organizacional al margen del propio actuar de los individuos, sin un cuestionamiento aparente y sin un juicio racionalizado de la forma en que se ejerce la dominación, como sugerimos en este trabajo para el concepto de legitimidad. En este sentido, se trata de una apelación impersonal y, en última instancia, coactiva de la actividad organizada, lo cual explica parcialmente el significado de la dominación en la administración,

${ }^{3}$ Subrayado en el original. 
pues así como es notoria la dominación a partir de la estructura orgánica, también existe en los hechos un proceso de legitimación en las relaciones de dominio que se producen en las organizaciones.

[...] "la institucionalización" y la "legitimación" [tendemos] a concebirlos como referentes a estructuras de roles referidas a actividades e interrelaciones basadas en normas o estándares internalizados en los actores que asumen los roles, y que por lo tanto representan un consenso general, aunque sólo sea implícito, acerca de lo que es justo y propio. Pero es fácil que saltemos a la conclusión de que cualquier estructura social concreta que persiste durante cierto tiempo debe, por consiguiente, estar institucionalizada o legitimada en un sistema de autoridad consensual. Sin embargo, hay una distancia muy notable entre el consentimiento amplio, voluntario o informado ante la demanda de los roles, por una parte, y la oposición manifiesta a los mismos, por otra (Buckley, 1993, p. 285). ${ }^{4}$

La institucionalización a la que se refiere Buckley se sustenta en un sistema normativo que parece entenderse como un mecanismo de legitimación. La crítica que advertimos en este autor es que la legitimación y la institucionalización son dos procesos diferentes, pues el hecho de que los individuos acepten como válido un sistema legalizado dista de ser comprendido como legítimo, únicamente por ser asumido por los actores; contrariamente, tiene un significado impositivo que los individuos lo aceptan por estar condicionado a la obligatoriedad en su cumplimiento porque responde a un ámbito de coerción implícito. La legitimidad no responde a este condicionamiento, sino que se justifica en un consentimiento amplio, voluntario e informado, al margen del contenido legalizado y, por consecuencia, sin posibilidades de una coacción manifiesta en las propias normas. Jürgen Habermas (1998) señala, en este sentido, lo siguiente:

El poder legítimo, de Max Weber, concentra la atención entre el nexo existente entre la creencia de la legitimidad y el potencial de justificaciones de ciertos ordenamientos, por un lado, y su validez fáctica, por el otro. La base de legitimidad permite conocer "los principios últimos en que puede apoyarse la 'vigencia' de un poder [...]". Lo solucionan mediante la coacción estructural, o sea, por medio del hecho de que las oportunidades legítimas de satisfacción de las necesidades se encuentran fijadas en un sistema de normas respetado. El reconocimiento fáctico de un sistema de normas de este tipo no se basa, desde luego, en la creencia de legitimidad que los gobernados alientan,

${ }^{4}$ Subrayados en el original. 
sino en el temor a las sanciones que constituyen una amenaza indirecta y la resignación ante ellas, así como en el mero dejar hacer teniendo en cuenta la impotencia percibida en uno mismo y la carencia de alternativa (pp. 117-118). ${ }^{5}$

La legitimidad no se reduce a la legalización de la función, sino a la necesidad de que los individuos reconozcan en el actuar concreto la posibilidad de asumir la funcionalidad del sistema a partir del acuerdo implícito entre ellos; es decir, el carácter legítimo en la organización no se determina por el aparato normativo, sino a partir de las acciones concretas que desarrollan los actores para el cumplimiento de sus actividades, por lo que el reconocimiento y la validez de las directrices funcionales únicamente pueden materializarse en los hechos, en el desarrollo de la acción. De esta manera, las formas en las que se legitiman los actos de autoridad posterior a la configuración de las reglas ya no obedecen a las condiciones establecidas formalmente, sino a la conformación del nivel funcional que asumen las personas para dar validez a las acciones.

En suma, la legalidad es una manifestación objetiva de la dominación debido a que se sustenta en un sistema de control plenamente identificado, como son las normas o la estructura orgánica, en tanto que la legitimidad tiene una connotación subjetiva de significado porque responde a un control sustentado en la conciencia de los individuos, a partir del convencimiento personal, de ahí que en la legitimidad no sea posible recurrir a ningún mecanismo de coacción individual o colectiva para ejercer algún tipo de dominación.

\section{El concepto de poder}

El concepto de poder en las relaciones sociales, en su ámbito más general, apunta a la influencia de ciertos actores sobre otros para lograr los propósitos de los primeros. Hemos señalado anteriormente que todo control social sugiere un sistema de dominación, incluso el que se ejerce dentro un ámbito de legitimación, por lo que toda dominación tiene como referente alguna forma de poder, entendido como una manifestación condicionada a algún aparato de dominio o un atributo de ciertos individuos para influir a otros en la consecución de determinados fines. La característica de esta definición es el dominio de una persona, en el que se plantea la

${ }^{5}$ Subrayado del autor. 
prevalencia de una acción frente a otra, de ahí que el poder adquiera una relevancia determinante en toda relación social. Michel Foucault (1988, pp. 11-12) señala que para el estudio del poder es necesario distinguir primero el que se ejerce sobre las cosas y proporciona la capacidad de modificarlas, utilizarlas, consumirlas o destruirlas y, por otra parte, el poder que pone en juego relaciones entre individuos (o entre grupos) porque, continúa, si se habla de estructuras o mecanismos de poder es sólo en la medida en que suponemos que ciertas personas ejercen poder sobre otras.

En este trabajo nos interesa abordar el concepto de poder como la relación entre los actores, no sólo a partir de su individualidad, es decir, entre un individuo y otro, sino entre grupos de personas, incluyendo estructuras de dominación. En las organizaciones, el poder se establece a partir de una serie de mecanismos esperados de conducta, bien sea por una suerte de control delimitado en una esfera particular de acción, sustentada en las directrices formales de comportamiento, o por alguna forma de influencia de uno o varios actores sobre otros, circunscrita a las orientaciones que señalan posibilidades de actuación en un sentido esperado. Mientras en el primero de estos casos el nombramiento jerárquico otorga la disposición de determinados actores para asumir funciones de control, independientemente del grado de legitimidad con la que se ejerce; en el segundo, las relaciones sociales guardan cierta reciprocidad con las acciones de todas las personas; esto es, tanto el individuo que ejerce la influencia como el actor influido crean un acuerdo intersubjetivo para ejercer y otorgar, respectivamente, una forma de actuación determinada por uno de ellos.

Michel Foucault (1988, pp. 12-13) señala que las relaciones de poder no pueden entenderse al margen de las actividades terminadas, ya sea las que permiten ejercer el poder (como las técnicas de entrenamiento, los procesos de dominación, los medios mediante los cuales se obtiene la obediencia) o las que recurren a relaciones de poder con el fin de desarrollar su potencial (la división del trabajo y la jerarquía de tareas), el cual hace referencia al poder institucionalizado, a una estructura de dominación como es la jerarquía en la administración. En ambos casos, el poder es una referencia orientada a fines, lo cual significa que en todo momento existe una justificación, explícita o implícita, de control de ciertas acciones sobre otras para asegurar un objetivo, lo cual se puede comprender más claramente en la administración, pues todo poder conferido por la estructura orgánica tiene como propósito fundamental el logro de objetivos. Henry Minztberg (1992, p. 5) define el poder como "la capacidad de afectar (causar efecto en) el comportamiento de las orga- 
nizaciones", en este sentido, continúa, el término poder denota tanto al sustantivo como al verbo que significa "ser capaz de". Y finaliza diciendo que "Tener poder es tener la capacidad de conseguir que determinadas cosas se hagan, de causar efecto sobre las acciones y decisiones que se toman". Advertimos que el poder en la administración no apunta a una manipulación, sino a una orientación objetiva del sentido de la acción hacia determinados propósitos (Mintzberg, 1992), lo cual es un atributo de la organización expresada en el aparato normativo, y que constituye una aceptación tácita de los individuos desde que se incorporan a ella, ésta es la razón por la que no podemos entender el poder a partir de esta dimensión como manipulación debido a que existe un consentimiento expreso y reconocido de los actores desde el momento en que éstos son parte de una organización.

Michel Crozier y Erhard Friedberg (1990, p. 55) indican que entrar en una relación de poder significa actuar sobre el prójimo, y "es en esta relación donde se desarrolla el poder de una persona A sobre una persona B"; para ellos "El poder es, pues, una relación y no un atributo de los actores". La posibilidad de que un individuo establezca algún tipo de influencia frente a otro u otros significa que el primero es capaz de definir una predominancia de objetivos, incluso particulares, sobre los demás, de manera que esta relación es capaz de orientar algún tipo de acción. El hecho de que el poder, como señalan Crozier y Friedberg, signifique "una relación y no un atributo de los actores" nos permite entender que el poder se manifiesta en la propia relación intersubjetiva, que incluso puede ser el resultado de un proceso de legitimación: "Así, el poder puede precisarse como una relación de intercambio, y por lo tanto recíproca, pero en la que las relaciones de intercambio favorecen más a una de las partes involucradas. Es una relación de fuerza de la cual uno puede sacar más ventaja que el otro, pero en la que, del mismo modo, el uno no está totalmente desvalido frente al otro" (Crozier y Friedberg, p. 58). ${ }^{6}$

Podemos entender que para Crozier y Friedberg el poder está sustentado en la posibilidad de que uno o varios individuos asuman subjetivamente algún tipo de influencia, incluso en igualdad de condiciones, con la finalidad de que uno de los actores obtenga ciertas ventajas de esta relación; en este caso estaríamos hablando tanto de una dominación legitimada como del nombramiento jerárquico que otorga el aparato de dominio en las organizaciones. Sin embargo, si el poder, como sugieren Crozier y Friedberg, es una relación, y si por relación entendemos el vínculo

${ }^{6}$ Subrayado en el original. 
que se establece intersubjetivamente entre las personas para la realización de una acción específica, entonces el poder concedido por la propia organización a través del nombramiento, en principio, ya no se sustenta en una relación particular de dominio entre los actores, sino en un atributo conferido formalmente; es decir, la relación de poder, en este sentido, se entiende como una relación entre el aparato de dominio y los individuos, de manera impersonal; la relación que se establece por este medio es intersubjetiva en el momento en que derive en un proceso de legitimación de la persona que dispone de la dominación otorgada por el aparato de dominio. La atribución de determinadas funciones que otorga la propia organización a ciertos actores es una fuente de poder determinante, en el que un derecho se concede formalmente, lo que lleva implícito, previamente a una relación concreta, el poder necesario que servirá como referente de control frente a los demás individuos. Desde esta perspectiva, el poder en la administración se otorga previamente a la relación intersubjetiva, y cuando el poder está fundado en la relación concreta entre los individuos estamos en condiciones de hablar de la legitimación del poder, que hemos definido en otros trabajos como la autoridad (Cruz, 2008 y 2010).

La posibilidad de discernir esta doble dimensión del poder, bien sea como el conferir un atributo o bien como una relación intersubjetiva, no es motivo de análisis en este trabajo; por el momento diremos que las fronteras conceptuales entre ambos ámbitos de explicación no son claras debido a que ambas dimensiones implican una relación entre individuos en continua interacción. El poder se establece a partir de algún tipo de influencia de uno o varios actores sobre otro u otros; en este sentido, observamos al poder como el sustantivo de una relación intersubjetiva; es decir, el poder como una probabilidad de acción entre muchas otras relaciones. Talcott Parsons analiza al poder como un medio del que dispone quien ejerce algún tipo de dominación para lograr un objetivo. En este sentido, la actividad sustantiva es la dominación, misma a la que está subsumido el poder.

Autoridad es la cualidad políticamente decisiva de un status en una estructura social. En cambio, el poder es, a mi modo de ver, un instrumento primordial para el desempeño eficaz en esa posición. A fin de ser eficaz, una unidad debe contar con un ingreso en forma de poder, estar dispuesto a gastarlo y, no obstante, proceder con prudencia en ese gasto. Esto puede significar que se transfiera poder a otras unidades de la colectividad o exteriores a ella. [...] El poder puede considerarse como un medio para controlar la acción intercambiable (Parsons, 1997, p. 124). ${ }^{7}$

${ }^{7}$ Subrayados en el original. 
Parsons atribuye a la autoridad una posición dentro de la estructura, en tanto que poder es un instrumento para ejercer la dominación. Se trata de entender al poder como un mecanismo para el ejercicio de la dominación. Según esta conceptualización, el poder es un elemento imprescindible en la relación social que se establece en la dominación, de manera que las condiciones prevalecientes en ella sirvan para el desempeño eficaz de la función. Esta connotación del poder responde al carácter excluyente de una de las partes, en la que el principal objetivo es el control de los procesos sociales y de los individuos.

Si bien es posible que el poder podemos ubicarlo dentro de las dimensiones de la legitimación de la autoridad, la explicación que hemos desarrollado responde en mayor medida a la imposición de ciertas directrices o acciones en aras de alcanzar ciertos objetivos, preponderantemente de índole particular y no comunitaria (Villoro, 2001, pp.79 y ss.). El poder, en este sentido, materializa la dominación.

[...] cabe definir el poder como control o influencia sobre las acciones de otros para promover nuestras metas sin el consentimiento de aquellos, contra su «voluntad», o sin su consentimiento o comprensión. [...] Los mecanismos implicados pueden abarcar la gama que va desde la fuerza desnuda, pasando por la manipulación de símbolos, la información, y otras condiciones ambientales, hasta la adjudicación de recompensas condicionales. El distingo reside en la falta de «consentimiento» [...].Una característica estrechamente relacionada es el acento en la orientación hacia metas privadas, más que en la orientación hacia metas de la colectividad (Buckley, 1993, p. 271).

Desde este punto de vista, el poder en la administración es una condición atribuible a algún aparato de dominio debido a que sólo éste puede condicionar el comportamiento colectivo en la organización mediante el elemento coercitivo, en la forma de recompensas - como un atributo expreso que otorga la propia organización al individuo dotado de autoridad para la consecución de sus objetivos - o mediante castigos de índole administrativa o el despido; en este sentido, compartimos la idea de que el poder tiende a estar más cercano a la imposición, independientemente del sustento sobre el que se edifica esa posibilidad (Cruz, 2006).

\section{El concepto de poder en la administración}

El breve análisis que hemos realizado en torno a los conceptos de legalidad y de legitimidad y el concepto de poder nos permite establecer elementos de estudio para comprender el significado del poder en la administración. Mientras la legalidad 
se funda en el aparato normativo de dominio que tiende a generar expectativas de funcionamiento impuestas, la legitimación se inscribe dentro de la validez implícita que otorgan los individuos que participan en una relación social, lo que contribuye a generar expectativas de funcionamiento organizacional más orientados al reconocimiento intersubjetivo, validadas por el actuar concreto de los actores. En este trabajo sostenemos que la legalidad define al poder en la administración.

Como lo hemos advertido en el estudio del poder que hemos realizado, podemos establecer dos dimensiones de análisis en torno al poder en la administración: por un lado, a partir de una estructura de dominación y, por otro, mediante las relaciones de poder que se producen dentro de las organizaciones. En ambos casos, los mecanismos de interacción social e individual apuntan a la comprensión de la dominación, incluso podemos señalar que, en cierta forma, la legitimidad es una manera de entender el poder, particularmente a partir de las relaciones de poder, como lo hemos mencionado anteriormente.

Tanto el poder que se produce en una estructura de dominación como en las relaciones sociales tienen un referente importante en la administración debido a la interrelación que se produce entre los individuos por ambas vías y porque el espacio de acción en donde se generan, las organizaciones, responden a espacios de interacción plenamente identificados, dentro de las cuales se originan una gran variedad de formas de poder. Michel Foucault (1988), refiriéndose a estas relaciones de poder, señala que es perfectamente legítimo analizarlas en instituciones bien determinadas, debido a que constituyen un "observatorio privilegiado para aprehenderlas, diversificadas, concentradas, puestas en orden y llevadas hasta su máxima eficacia". Asimismo, indica que en las instituciones ${ }^{8}$ es en donde podría encontrarse la aparición de la forma y la lógica de sus mecanismos elementales.

Sin embargo, el propio Foucault señala que el estudio del poder en las organizaciones, que se genera a partir de los espacios institucionales, representa una dificultad para su análisis, pues existe la posibilidad de que únicamente se entienda a partir de su propia dinámica de funcionamiento, sin atender a las relaciones sociales concretas de sus integrantes.

\footnotetext{
${ }^{8}$ Por ahora no es nuestra intención distinguir instituciones de organizaciones; pensamos que las instituciones a las que se refiere Foucault son lo que entendemos como organizaciones.
} 
Sin embargo, el análisis de las relaciones de poder en espacios institucionales cerrados presenta cierto número de inconvenientes. Primero, el hecho de que una parte importante de los mecanismos que pone en práctica una institución estén destinados a asegurar su propia conservación, conlleva el riesgo de descifrar funciones esencialmente reproductivas, en particular en las relaciones de poder "interinstitucionales". Segundo, el analizar las relaciones de poder a partir de las instituciones, se expone uno a buscar la explicación y el origen de éstas en aquéllas, esto es, a explicar, en suma, el poder por el poder (Foucault, 1988, p. 17).

Los dos riesgos que presenta el estudio del poder en la administración que indica Foucault se circunscriben a la estipulación del aparato normativo de dominio, el cual permite el cumplimiento de los objetivos organizacionales, como su mecanismo de "conservación y reproducción"; es claro que la función legalizada que hemos expuesto en torno a la administración garantiza formas de funcionamiento internas y ésta es la razón por la que la fuente de explicación del poder en la administración se circunscriba a este ámbito de significado. La crítica que plantea Foucault, en este sentido, es muy válida; sin embargo, los elementos de análisis que disponemos para entender la dominación en la administración necesariamente tiene su referente en la estructura orgánica debido a que es en ella donde se generan los mecanismos de participación funcionales que permiten el cumplimiento de los objetivos organizacionales, de ahí que partamos de la idea que la comprensión del poder se limite a este ámbito, y que la legitimidad sea una posibilidad de estudio que explique a la autoridad (Cruz, 2008) y no al poder, como de hecho sucede en la administración en las organizaciones. Pensamos que el estudio de las relaciones de poder al margen de la estructura de dominio que contiene la estructura orgánica en la administración corresponde estudiarla desde el ámbito sociológico o psicológico, lo cual no cancela la oportunidad de que su estudio se realice bajo estas directrices en la teoría de la administración o en las teorías organizacionales.

Las opciones de estudio que advertimos en Foucault para entender el fenómeno del poder podemos ubicarlas a partir de un aparato de dominio, que en la administración estaría supeditado a la estructura orgánica, y mediante las relaciones sociales que se establecen entre los individuos. Si bien en la administración es posible el estudio de ambas vertientes de análisis, inicialmente lo consideraremos a partir de la estructura orgánica por las razones antes expuestas y porque ésta constituye uno de los principales mecanismos de los que se han valido las organizaciones para determinar los cursos de acción de los individuos, en donde quienes ostentan un cargo jerárquico poseen las atribuciones de dominio para orientar el sentido de 
la función, en el mejor de los casos, o los mecanismos coactivos de dominio para exigirlo, al margen de su carácter legítimo.

Pensamos que la principal fuente de poder en la administración es el corpus normativo, del que se originan las acciones de los miembros en la organización, aunque los grados en los que se ejercen varían de un tipo de organización a otra, e independientemente de que éste tenga o no que legitimarse. Por ejemplo, en el gobierno, el ejercicio del poder es tan amplio que puede obedecer desde el carácter legítimo de las políticas públicas u obedecer a la imposición de las mismas hasta con la fuerza física. En el caso del ejército, lo que determina en última instancia la dominación es el contenido impositivo de las órdenes, por lo que el poder personal tiene mayor relevancia que, incluso, lo que indican las propias reglas; sucede lo contrario en los partidos políticos u organismos sociales, en los que el poder se subsume a la capacidad de persuasión o convencimiento, mediante la manipulación de símbolos o la justificación de recompensas. En todos los casos existe un aparato de dominio que justifica el proceder individual o colectivo de los miembros que conforman la organización.

La propia estructura administrativa otorga el poder a los actores para enmarcar el comportamiento de todos sus participantes en las directrices que ella señala, incluso el poder en estos ámbitos funge como elemento de intercambio, por ejemplo, ciertas concesiones, estímulos o premios a todos los participantes cumplen como mecanismos de control para esperar su obediencia y, de esta manera, los actores quienes ejercen la dominación disponen de ciertos elementos de dominio para esperar o exigir el cumplimiento de las directrices de acción.

Creemos que posee mayor significado para el análisis de la sociedad moderna la introducción explícita del concepto de «poder institucionalizado formalmente» como tipo polar opuesto al de «autoridad institucionalizada formalmente». [...] esta distinción señala explícitamente que el poder es siempre poder, ya que está institucionalizado o que se manifiesta de otro modo. Es decir, el control sobre otros mediante una estructura sociocultural normativa, por lo menos legalizada en parte, que se basa, de cierto modo discernible, en alguna forma de coerción latente o manifiesta que actúa sobre los grupos directamente o a través del medio respectivo, y que mantiene unida una estructura de orientaciones hacia metas privadas (Buckley, 1993, p. 284). ${ }^{9}$

${ }^{9}$ Subrayado del autor. 
La connotación de la dominación que nos interesa analizar, en este sentido, es la dimensión concerniente al poder que otorga la propia estructura, y que se mantiene en los ámbitos funcionales de las organizaciones mediante la estructura jerárquica. La capacidad de dominio que sustenta al poder, desde esta perspectiva, es la posibilidad de coerción para el cumplimiento de la norma. Peter M. Blau define al poder de la siguiente manera: "El poder es la capacidad de las personas o los grupos para imponer su voluntad sobre otros a pesar de la resistencia, mediante la disuasión que adopta la forma de retención de recompensas otorgadas regularmente [coerción positiva], o bajo la forma de castigos, en cuanto la primera tanto la última constituyen, en efecto, una sanción negativa" (citado por Buckley, 1993, p. 293). En ambos escenarios se mantiene el elemento coactivo que define al poder en la administración, lo que deviene como posibilidad en un ejercicio arbitrario de la dominación debido a la discrecionalidad con la que actúan regularmente los individuos que se encuentran dentro de una estructura jerárquica: el poder, en palabras de Max Weber, como "la posibilidad de imponer la propia voluntad, dentro de una relación social aun contra toda resistencia y cualquiera que sea el fundamento de esa probabilidad" (Weber, 1999, p. 43); es decir, la de imputar el carácter dominante de la relación social que se produce en la administración, que va desde la adecuación plena a las normas existentes hasta la posible arbitrariedad en el orden. En ambos casos, el concepto de poder que indica Max Weber mantiene los elementos coercitivos de dominio como última instancia de validez.

La única explicación posible, bajo esta premisa, es entender "el poder por el poder", en palabras de Foucault: "[...] en la medida en que las instituciones actúan esencialmente poniendo en juego dos elementos, reglas (explícitas o silenciosas) y un aparato, se corre el riesgo de darle a uno o a otro un privilegio exagerado en la relación de poder y, por lo tanto, de ver en estas últimas únicamente modulaciones de la ley y de la coerción" (1988, pp. 16-17) ${ }^{10}$ La correspondencia que existe entre la jerarquía y los demás individuos en la administración está determinada por el grado de poder que se deriva de la estructura orgánica, al margen de la legitimación funcional.

La "autoridad conferida" siempre falla, porque la facultad para la misma la desarrolla el individuo mismo; proviene de las interacciones entre las personas, donde se gana el respeto. La manera más efectiva de ejercer la autoridad consiste en las órdenes despersonalizadas, con énfasis en la importancia de las tareas, más que en los derechos que una persona tiene sobre otra (Kanter, 1997, p. XIV).

${ }^{10}$ Subrayado del autor. 
Estas atribuciones de la estructura jerárquica, en realidad, no conforman una relación de dominio individual, sino que forman parte de la propia capacidad que otorga la organización para alcanzar sus metas, debido a que quien verdaderamente cuenta con el poder es el propio sistema funcional en el que participan los actores. Para Hans-Georg Gadamer, este sistema de dominio "encuentra su expresión más visible en el concepto de función y en el papel del funcionario. Esta expresión manifiesta la subordinación a un sistema y la dependencia de este sistema, en el cual a cada uno le está predestinada una función" (2000, pp. 102-103). Y más adelante señala: "El dominio absoluto de este sistema no dura más que el de un individuo o el de una clase dominante. No se trata de un déspota que pueda ser destronado. No se trata del anonimato de un dominio que nos incluye a todos. [...] En verdad nadie tiene el poder, todos son sus servidores" (p. 104). ${ }^{11}$ En la administración, las normas impersonales son el mecanismo de control del poder y de las acciones individuales porque limitan la conducta de los actores y permiten asegurarle al sistema un orden establecido, por esto el significado del poder en la administración responde a un carácter permanente de dominación: "el ideal del orden legalmente asegurado ilimitadamente, y con ello la sola tiranía de la función deviene determinante. La tiranía de la función es la tiranía del sistema en el que uno está encadenado y que le obliga al mismo tiempo a identificarse con él" (Gadamer, 2000, p. 106).

\section{Conclusión}

El aparato de dominio en el que se justifica el poder en la administración obedece al sistema legal imperante, el cual debemos entenderlo a partir de la estructura orgánica que sustenta el nivel funcional con el que actúan los individuos dentro de las organizaciones. La dominación que se ejerce a partir de este sistema de dominio es impersonal debido a que responde a un mecanismo de participación sustentado en las normas y, por lo tanto, quien ejerce la dominación no requiere la legitimación, sino que su acción es capaz de justificarse por sí misma apelando a la legalidad imperante, con lo cual el elemento coercitivo de dominio se convierte en un mecanismo latente de control. La propia estructura orgánica provee de las directrices de funcionamiento que le servirán para orientar el trabajo colectivo hacia los objetivos organizacionales.

\footnotetext{
${ }^{11}$ Subrayado del autor.
} 
El poder otorgado por un aparato de dominio no sólo proyecta escenarios de control totalitario, sino que también tiende a generar, en el mejor de los casos, orientaciones de acción desde la jerarquía plenamente legitimadas y, por lo tanto, validado fácticamente, al margen del elemento coercitivo dispuesto por la estructura orgánica. El concepto de poder en la administración podemos explicarlo a partir de tres dimensiones de análisis: en primer término, desde la estructura orgánica en la que se materializa el aparato de dominio imperante en una organización; en segundo, como la relación intersubjetiva que se produce entre los individuos, a la que Foucault ha llamado como las relaciones de poder; y, por último, el poder que se genera mediante los procesos de legitimación que se producen a partir de la estructura orgánica, los cuales apuntan a un vínculo conceptual entre la concepción de la dominación desde un aparato de dominio y las relaciones intersubjetivas; es decir, la legitimidad de la dominación apuntaría al necesario estudio del poder desde la legalidad, del poder institucionalizado del que habla Foucault, y al análisis de las relaciones intersubjetivas que ha denominado este autor como las relaciones de poder.

\section{Referencias}

Buckley, W (1993). La sociología y la teoría moderna de los sistemas. Tr. Aníbal C. Leal. Buenos Aires: Amorrortu.

Crozier, M. y E. Friedberg (1990). El actor y el sistema. Las restricciones de la acción colectiva. México: Alianza Editorial Mexicana.

Cruz, L. A. (2006). La regularidad del comportamiento administrativo a partir del concepto de dominación de Max Weber. Contaduría y administración, enero-abril, (218): 61-85.

(2008). El concepto de legitimidad de la autoridad: elementos de análisis para comprender la relación autoridad-subordinación en el comportamiento administrativo. Academia. Revista Latinoamericana de Administración, primer semestre, (40): 68-82.

(2010). El concepto de autoridad en el pensamiento de Aristóteles y su relación con el concepto de autoridad en el comportamiento administrativo. Contaduría y Administración, mayo-agosto, (231): 53-78. 
Foucault, M. (1988). El sujeto y el poder. Revista mexicana de sociología, julio-septiembre, (3): 3-20.

Gadamer, H. (2000). La idea de la tolerancia. Elogio de la teoría. Tr. Anna Poca. Barcelona: Península, 23-44.

Kanter, R. M. (1997). Prefacio. En Pauline Graham (ed.). Mary Parker Follett. Precursora de la administración. Tr. Carmen Aspe Solórzano. México: McGraw Hill, XIII-XIX.

Habermas, J. (1998). Problemas de legitimación en el capitalismo tardío. Tr. José Luis Etcheverry. Buenos Aires: Amorrortu, 113-119.

Mintzberg, H. (1992). El poder en la organización. Tr. Josep M. Comajuncosa. Barcelona: Ariel.

Parsons, T. (1997). El aspecto político de la estructura y el proceso sociales. En David Easton (comp.). Enfoques sobre teoría política. Tr. José Rovira Armengol. Buenos Aires: Amorrortu.

Terry, G. R. (1982). Principios de administración. Tr. Alfonso Vasseur Walls. México: CECSA.

Villoro, Luis (2001). El poder y el valor. Fundamentos de la ética política. México: Fondo de Cultura Económica-El Colegio Nacional.

Weber, M. (1990). Economía y sociedad. 2a ed. Tr. José Medina Echavarría et al. México: Fondo de Cultura Económica. 
